\title{
Short-Chain Fatty Acids Calibrate RAR $\alpha$ Activity Regulating Food Sensitization
}

OPEN ACCESS

Edited by:

Silvia Melgar,

University College Cork, Ireland

Reviewed by:

John MacSharry,

University College Cork, Ireland

Kathryn A. Knoop,

Mayo Clinic, United States

*Correspondence:

Zhigang Liu

Izg@szu.edu.cn

Zongde Zhang

zongdez@swmu.edu.cn

${ }^{\dagger}$ These authors have contributed equally to this work and share first authorship

Specialty section:

This article was submitted to

Mucosal Immunity,

a section of the journal

Frontiers in Immunology

Received: 07 July 2021

Accepted: 20 September 2021

Published: 14 October 2021

Citation:

Yuan $X$, Tang $H$, Wu R, Li X, Jiang $H$,

Liu Z and Zhang Z (2021) Short-Chain

Fatty Acids Calibrate RAR $\alpha$ Activity

Regulating Food Sensitization.

Front. Immunol. 12:737658.

doi: 10.3389/fimmu.2021.737658

\author{
Xiefang Yuan ${ }^{1 \dagger}$, Hongmei Tang ${ }^{1 \dagger}$, Renlan $\mathrm{Wu}^{1}$, Xingjie $\mathrm{Li}^{1,2}$, Hongyu Jiang ${ }^{1,2}$, \\ Zhigang Liu $^{3 *}$ and Zongde Zhang ${ }^{1,2 *}$
}

1 Inflammation \& Allergic Diseases Research Unit, Affiliated Hospital of Southwest Medical University, Luzhou, China, ${ }^{2}$ The
School of Basic Medical Sciences, Southwest Medical University, Luzhou, China, ${ }^{3}$ State Key Laboratory of Respiratory
Disease for Allergy at Shenzhen University, Shenzhen University School of Medicine, Shenzhen, China

Gut-microbiota dysbiosis links to allergic diseases. The mechanism of the exacerbation of food allergy caused by gut-microbiota dysbiosis remains unknown. Regulation of retinoic acid receptor alpha (RAR $\alpha$ ) signaling is critical for gut immune homeostasis. Here we clarified that RAR $\alpha$ in dendritic cells (DCs) promotes Th2 cell differentiation. Antibiotics treatment stimulates retinoic acid signaling in mucosal DCs. We found microbiota metabolites short-chain fatty acids (SCFAs) maintain IGF-1 levels in serum and mesenteric lymph nodes. The IGF-1/Akt pathway is essential for regulating the transcription of genes targeted by RAR $\alpha$. And RAR $\alpha$ in DCs affects type I interferon (IFN-I) responses through regulating transcription of IFN- $\alpha$. Our study identifies SCFAs crosstalk with RAR $\alpha$ in dendritic cells as a critical modulator that plays a core role in promoting Th2 cells differentiation at a state of modified/disturbed microbiome.

Keywords: allergy, dendritic cell (DC), microbiota, short-chain fatty acids (SCFAs), type I interferon (IFN-I)

\section{INTRODUCTION}

Vitamin A plays a crucial role in maintaining homeostasis at the intestinal barrier and balancing immunity and tolerance. As its principal active metabolite, retinoic acid (RA) implicates diverse inflammatory responses, which affect innate and adaptive immunity (1). RA involved in immunological procession regulates gene expression through binding several families nuclear hormone receptor, including retinoic acid receptors (RARs) $\alpha, \beta$, and $\gamma$, retinoid X receptors (RXRs) $\alpha, \beta$ and $\gamma$, and the peroxisome proliferator-activated receptors (PPARs) $\beta, \delta$ (2). The RAR family includes RAR $\alpha$, RAR $\beta$, and RAR $\gamma$. Lack of RA associates with abnormal migration of immune cells to the intestine and impaired immune tolerance $(3,4)$. RAR $\alpha$ is the dominant retinoic acid signaling transcription factor in DCs (5). However, whether RAR $\alpha$ in DCs regulates immune response, especially the $\mathrm{T}$ cell differentiation, is not clear.

RA signaling implicates the imbalance of gut immune maintenance caused by microbiota dysbiosis (6). And microbiota colonized has played a crucial role in developing the intestinal immune system (7). Microbial components and metabolites produced by gut microbiota participate in various host processes $(8,9)$. Short-chain fatty acids (SCFAs) are the most studied microbial metabolites produced by gut flora through the fermentation of polysaccharides. SCFAs associates 
with the maturation of the immune system, including induction of peripheral regulatory $\mathrm{T}$ cells, protection from infection, and modulation of metabolic rate and energy homeostasis (7).

Allergic diseases exert a devastating global impact and lack effective vaccines or advanced therapeutics. Allergic inflammation is a type 2 immune disorder classically characterized by the high level of immunoglobulin $\mathrm{E}$ (IgE) and the development of Th2 cells (10). Basic understanding of the critical cell types and mediators that initiate and modulate type 2 immunity is limited. Recently, type I interferons (IFN-I) were shown to cause Th2-cells differentiation (11). IFN-I is most wellknown for its pro-inflammatory role in antiviral immunity. Many IFN-I effects are mediated by a direct impact on DC phenotype and functionality. IFN-I responsiveness controls the ability of $\mathrm{cDC} 1$ s to present viral antigens to CD8+ T cells (12) and influences DC activation, migration, and $\mathrm{T}$ cell priming in vitro. DC-intrinsic IFN-I signaling is required for their effective migration, localization, and Th2 response in vivo (13).

This study showed that RAR $\alpha$ in DCs was involved in the microbiota dysbiosis-induced exacerbation of food allergy. Loss of dendritic cells RAR $\alpha$ repressed Th2-cell differentiation. Gut dysbiosis caused a reduction of IGF-1 expression in $\mathrm{mLN}$ tissue and induced hyperresponsiveness of RA signaling and IFN-I response in mLN. And the IGF-1/Akt pathway has been implicated in the suppression of RA signaling and IFN-I response by regulating $\operatorname{RAR} \alpha$ transcriptional ability in vivo. These findings identify that RAR $\alpha$ serves as a regulatory node in food allergy. The IGF-1/Akt pathway inhibits RA signaling and IFN-I response, which played a positive role in Th2cell differentiation.

\section{RESULTS}

\section{Retinoic Acid Signaling Is Required for Gut Microbial Dysbiosis-Induced Allergy}

Intestinal epithelial and dendritic cells are the main sites of retinoic acid metabolism in the intestinal tissues $(14,15)$. Specific intestinal microbiota can modulate retinoic acid signaling in intestinal epithelial cells and DCs $(16,17)$. To assess whether gut bacteria have an effect on retinoic acid (RA) signaling, we established an animal model with gut microbiota dysbiosis by treating mice with a cocktail of antibiotics, and RA signaling reporter mice which harbored a RA response element (RARE) upstream of $\beta$-galactosidase ( $\mathrm{LacZ}$ ) were used. The LacZ expression in epithelial and dendritic cells in mesenteric lymph nodes $(\mathrm{mLN})$ was measured by flow cytometry. Then we found that mice treated with antibiotics preserved a higher level of RARE transcription in dendritic cells in mLN (Figures 1A, B). However, ablation of gut bacteria have no effect on RARE transcription level in intestinal epithelium (Figures 1A, B). Furthermore, we observed a higher expression of several RAresponsive genes in mesenteric tissue after antibiotics treatment (Figure 1C) using real-time quantitative PCR. These results indicate that gut bacterial regulation of RA signaling was specific in intestinal dendritic cells.
To explore whether partially depletion of gut microbiota could exacerbate food allergy, an animal model allergic to OVA was build. Consistent with other animal experiments (18), a higher level of OVA-specific IgE, IgG1 were observed in ABX treated mouse compared to untreated mouse (Figures 1D, E). We hypothesized that RA signaling was involved in antibioticinduced food allergy.

To evaluate the RA signaling impact on allergic intestinal inflammation, we generated a cell-specific loss-of-function mouse model of RAR $\alpha$. We generated $c d 11 c^{\mathrm{cre}} \mathrm{RAR} \alpha^{\mathrm{fl} / \mathrm{fl}}$ mice that lack RAR $\alpha$ in cd11c positive dendritic cells (RARA ${ }^{\Delta \mathrm{DC}}$ ). The number of CD4(+) and CD8(+)T cells in the spleen did not be affected by the loss of RAR $\alpha$ in dendritic cells in our previous study (19). In an OVA-allergic animal model, we observed that a decreasing number of CD4(+)IL4(+) cells in RARA $^{\Delta \mathrm{DC}}$ mice compared to RARA ${ }^{\mathrm{f} / \mathrm{fl}}$ mice (Figure 1G), indicating that RAR $\alpha$ in dendritic cells plays an essential role in Th2 cell differentiation.

\section{Gut Dysbiosis Regulates the IGF-1/Akt Pathway in Mesenteric Lymph Tissue}

Gut microbiotas inhabit the gut and affect host physiology. Gut microbiota dysbiosis, which could be induced by antibiotics abuse or microbial environmental change, has been involved in several disease processes. A recent study identified the role of gut microbiota in the regulation of bone growth by affecting circulating IGF-1 levels (20). We confirmed that the reduction of circulating IGF-1 production in $\mathrm{ABX}$ mice compared to untreated mice (Figure 2A). qPCR analysis revealed that intestinal bacteria ablation diminished the IGF-1 expression in $\mathrm{mLN}$ tissue. However, we did not detect IGF-1 expression differences in Peyer's patches, spleen, and intestinal tissues, including colon, jejunum, ileum. (Figure 2B).

Meanwhile, we measured the protein level of Akt and its phosphorylation level, one of the most crucial molecule targets of IGF-1. We found a reduction of Akt phosphorylation level in the mesenteric lymph node after antibiotic depletion of gut microbiota coincided with decreased IGF-1 production in mLN, while the Akt phosphorylation level did not change in the spleen (Figures 2C, D). Moreover, we detected the Akt phosphorylation level in dendritic cells, $\mathrm{T}$ cells, and $\mathrm{B}$ cells in $\mathrm{mLN}$ and spleen tissue. We observed that in comparison to untreated mice, ABX mice had a decreased level of Akt phosphorylation in mLN dendritic cells (Figures 2E, F). These data suggest that gut bacteria regulates IGF-1 production to modulate Akt phosphorylation in dendritic cells specifically in $\mathrm{mLN}$.

\section{IGF-1/Akt Pathway Inhibits the RA Response Through Enhancing RARA Phosphorylation}

RAR $\alpha$ activates transcription of retinoic acid response-related genes through its dimerization with RXRa. And RAR $\alpha$ transactivation is regulated by its Phosphorylation. RARs have been reported to be substrates for PKA (protein kinase A), PKC. Akt, a serine/threonine kinase, phosphorylates RAR $\alpha$ to reduce its transactivation ability in NSCLC cells (21). Next, we wanted 


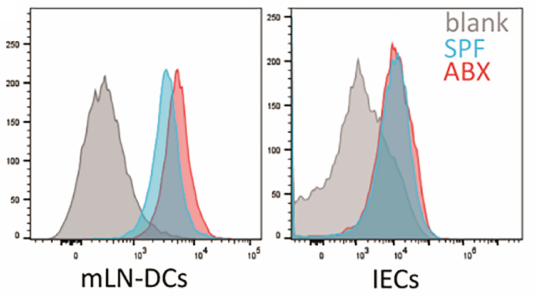

C

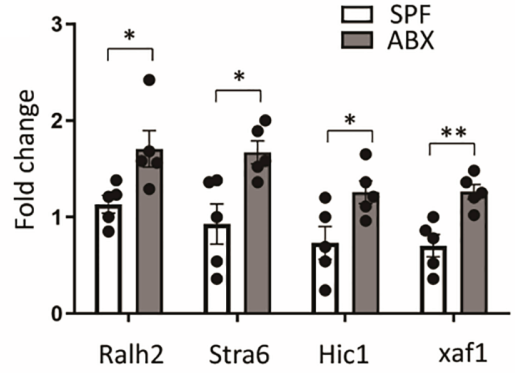

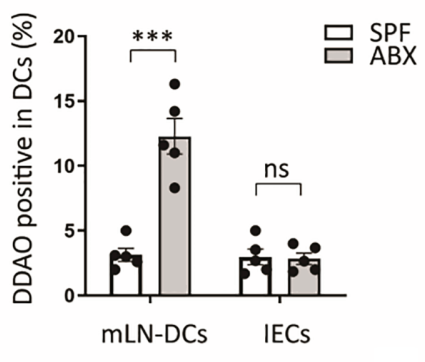

D

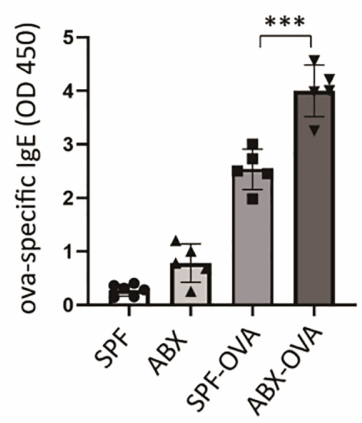

E

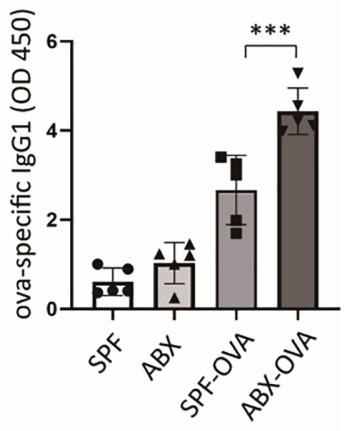

$\mathbf{F}$
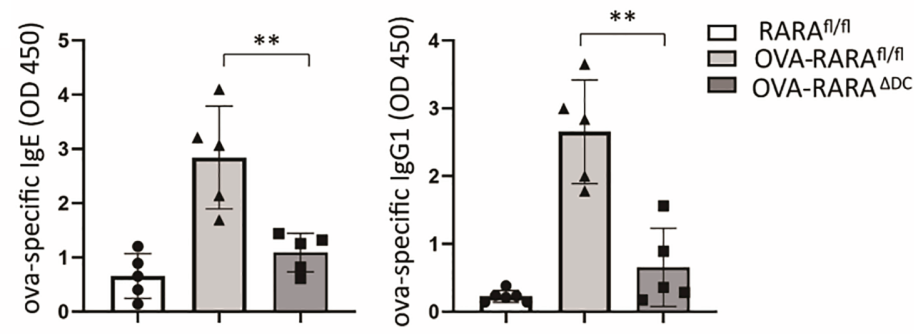

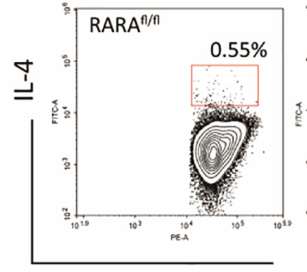

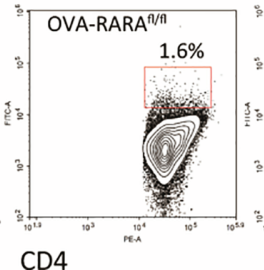

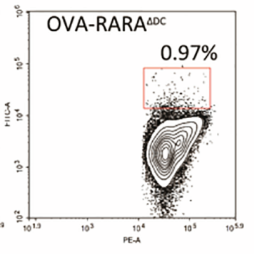

H

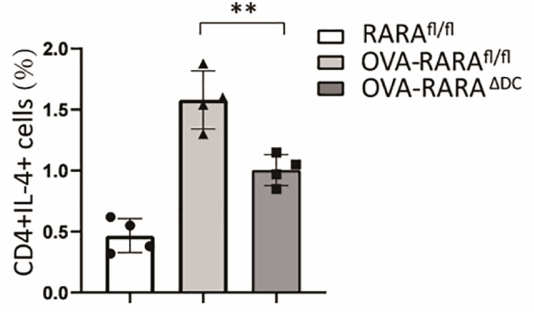

FIGURE 1 | RA signaling is required for gut dysbiosis-induced allergy. (A, B) RA signaling assessment. $\beta$-galactosidase expression was detected by its substrate DDAOG using flow cytometry. DCs (gating on cd11c positive) from $\mathrm{mLN}$ tissue and intestinal epithelial cells (IECs) isolated from RARE-lacZ transgenic mice were analyzed. (C) RT-PCR measurement of retinoic acid signaling-related genes, relative to Gadph, in $m L N$ tissue. (D-F) RAR $\alpha^{\mathrm{fl} / \mathrm{fl}}$ and RAR $\alpha^{\Delta \mathrm{DC}}$ mice, after treated with ova intragastric administration, ova-specific lgE and lgG1 levels in serum were detected by ELISA. And the frequency of CD4(+)IL4(+) cells in mLN were measured by flow cytometric analysis. Graph shows mean and SEM. Five mice per group from at least two independent experiment. Data were analyzed by unpaired Student's t-test (A-C) and one-way ANOVA (D-H). ${ }^{*} p<0.05,{ }^{* *} p<0.01,{ }^{* *} \mathrm{p}<0.001$, ns, not significant.

to assess whether IGF-1 modulated RAR $\alpha$ transactivation by regulation of Akt phosphorylation. We used tamibarotene, a $\mathrm{RAR} \alpha$ specific agonist, to induce RA response. In vitro experiment demonstrated that IGF-1 inhibits RARE transcription level stimulated by tamibarotene in BMDC (Figures 3A, B). In the western blot experiment, tamibarotene significantly reduced the phosphorylation of RAR $\alpha$ in BMDCs.
And we found that IGF-1 increased Akt phosphorylation level, and also RAR $\alpha$ phosphorylation level in BMDCs compared to BMDCs stimulated with tamibarotene alone. (Figures 3C, D). Furthermore, MK2206, an Akt phosphorylation inhibitor, suppressed the Akt phosphorylation level induced by IGF-1 and reduced RAR $\alpha$ phosphorylation level caused by IGF-1 (Figures 3C, D). These results establish that IGF-1 increases 


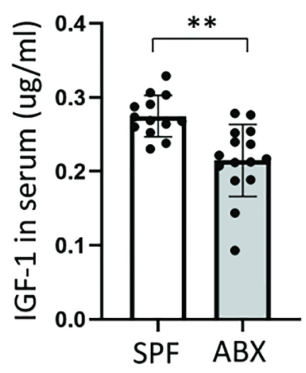

B
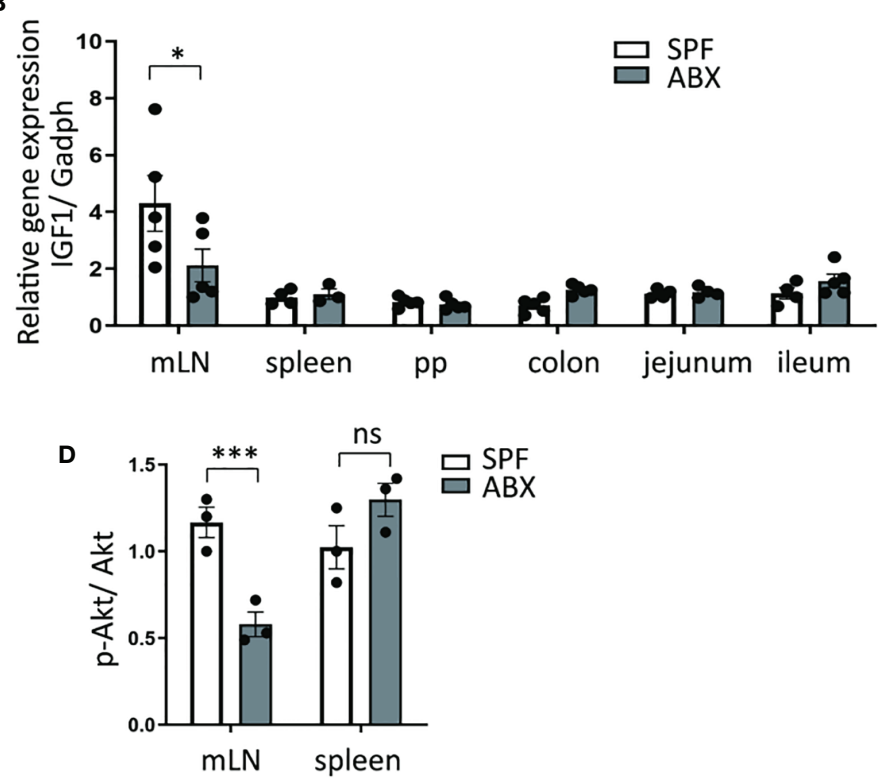

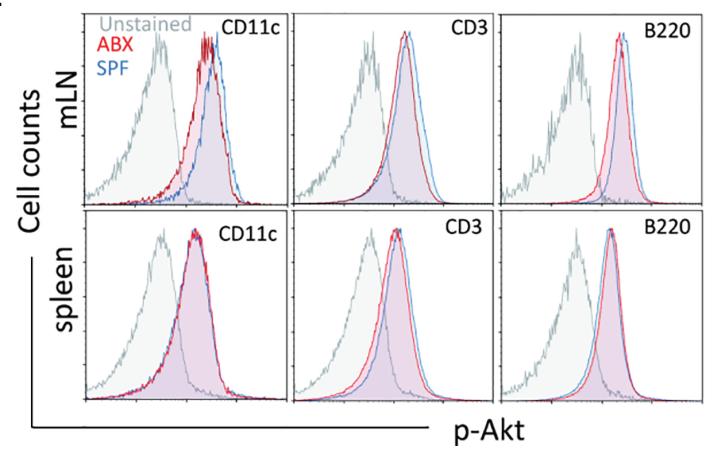

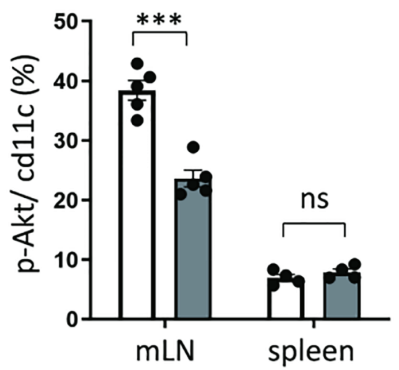

FIGURE 2 | Gut dysbiosis regulates the IGF-1/Akt pathway in mesenteric lymph tissue. (A) After mice treated with ABX, IGF-1 ELISA was performed on serum. (B) And mRNA expression of IGF-1 in mLN, spleen, Peyer's Patches (PP), colon, jejunum, ileum tissues, were measured by RTPCR. (C, D) p-Akt and Akt protein level change in $\mathrm{mLN}$ and spleen were determined by western blotting. (E) p-Akt expression levels of DCs (cd11c+), T cells (CD3+), B cells (B220+) in mLN and spleen were measured by flow cytometry. (F) Graph shows frequency of p-Akt positive DCs in $m L N$ and spleen. As shown, $p$-Akt protein level of DC in $m L N$ was reduced in ABX mice. Graph shows mean and SEM. (A) Data are combined from two independent experiments with at least thirteen mice per group. Graph shows mean and SEM. Data were analyzed by unpaired Student's t-test. ${ }^{*} \mathrm{p}<0.05,{ }^{* *} \mathrm{p}<0.01,{ }^{* * *} \mathrm{p}<0.001$, ns, not significant.

RAR $\alpha$ phosphorylation through the Akt pathway to reduce $\mathrm{RAR} \alpha$ transactivation ability.

\section{Retinoic Acid Receptor Alpha Regulates Type I Interferons and stat1 Expression}

Type 2 immunity plays a crucial role in classic allergic diseases. Despite inflammatory mediators, cytokines, or innate immune cells influence type 2 immunity, and DCs must affect activation and polarization of type 2 immunity (22). IFN-I is well known for its antiviral immunity. However, several studies provide evidence that IFN-I signaling enhances the ability to polarize the type 2 immunity $(23,24)$. By in vitro experiment, the expression of IFN-I related genes was assessed through qPCR after stimulation of tamibarotene, a RAR $\alpha$ specific agonist. The expression of IFN- $\alpha$ and IFN- $\beta$ (Figures 4A, B) in BMDCs, the main subtypes of IFN-I, was increased after tamibarotene stimulation. Interestingly, IGF-1 could interfered with tamibarotene's ability to exacerbate IFN-I expression in BMDC (Figures 4A-E). Further, to determine whether RAR $\alpha$ affects IFN-I signaling, BMDC lacking RAR $\alpha$ expression generated from $c d 11 c^{c r e} R A R \alpha^{\mathrm{fl} / \mathrm{fl}}\left(\mathrm{RARA}^{\Delta \mathrm{DC}}\right)$ mice were used for experiments. The mRNA expression of IFN- $\alpha$, IFN- $\beta$ were significantly down-regulation in BMDC from RARA $^{\Delta \mathrm{DC}}$ mice compared to RARA ${ }^{\mathrm{f} / \mathrm{fl}}$ mice (Figures $4 \mathrm{~A}, \mathrm{~B}$ ). In addition, the IFN-stimulated genes (ISGs) IFIT1, IFIT2, and MX1, were also upregulated by treating tamibarotene and restricted by IGF-1 and RAR $\alpha$ expression (Figures 4A-E).

We also checked by chromatin immunoprecipitation (ChIP) whether RAR $\alpha$ binds to the promoter region of IFN- $\alpha$, IFN- $\beta$ to investigate the mechanism of how RAR $\alpha$ regulates IFN-I signaling. We confirmed that $\operatorname{RAR} \alpha$ was bond to the promotor 
A

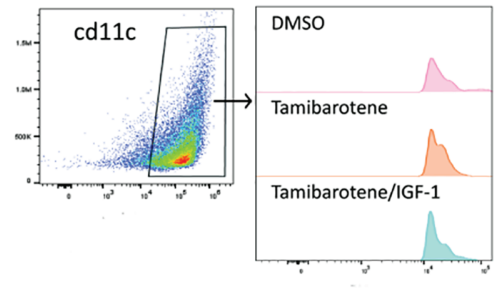

B

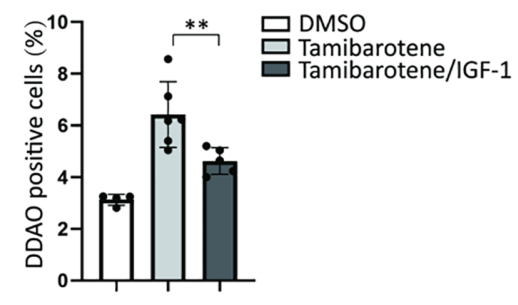

C

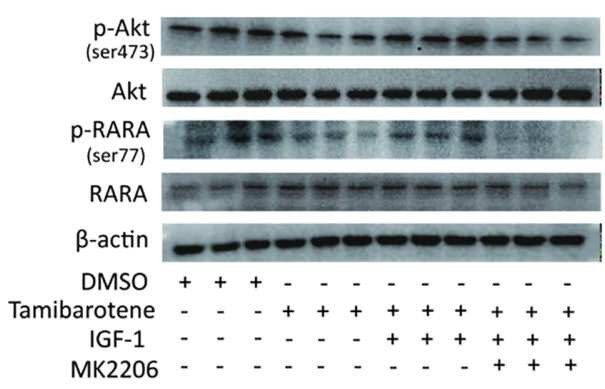

D

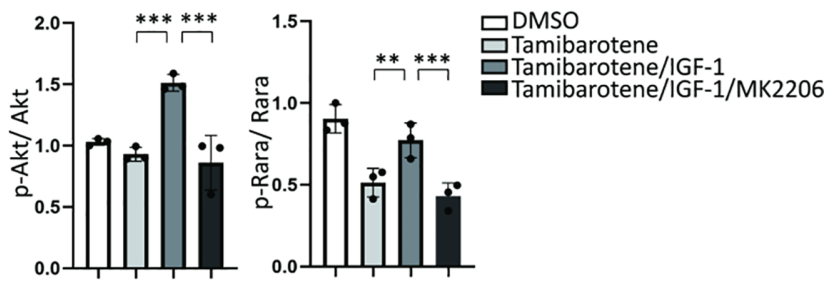

FIGURE 3 | IGF-1/Akt pathway inhibits the RA response through enhancing RARA phosphorylation. (A, B) RA signaling assessment. BMDCs cultured from RARElacZ transgenic mice were treated with DMSO, Tamibarotene $(4 \mathrm{mM})$ alone or with IGF-1 (500ng/ml).DDAO signaling were measured by flow cytometry after BMDC treated with substrate DDAOG. (C, D) BMDCs were cultured from normal SPF mice, and treated with DMSO, Tamibarotene, IGF-1 and Akt inhibitor (MK2206), then p-Akt, Akt, p-RAR $\alpha$, RAR $\alpha$ expression were detected by western blotting. Data are from two or three independent experiments. Graph shows mean and SEM. Data were analyzed by one-way ANOVA. ${ }^{\star *} p<0.01,{ }^{\star \star *} p<0.001$.

region of IFN- $\alpha$, but not IFN- $\beta$ (Figure 4F). Furthermore, we detected significantly higher enrichment of RAR $\alpha$ in IFN- $\alpha$ binding sites in BMDC treated with tamibarotene compared with PBS-treated BMDC (Figure 4F).

Previous reports indicate that RAR $\alpha$ regulates statl expression through the binding RARE site in stat1 promoter $(25,26)$. We tested the stat1 protein level after BMDC was treated with tamibarotene and found that tamibarotene increased stat1 protein expression (Figure 4G). The reduction of Statl expression in BMDC from $\mathrm{RARA}^{\Delta \mathrm{DC}}$ mice compared to RARA ${ }^{\mathrm{fl} / \mathrm{fl}}$ mice was observed by the immunofluorescence method (Figure 4H). Taken together, the results indicate that $\mathrm{RAR} \alpha$ in DCs regulate type I interferons signaling by modulating transcription of IFN- $\alpha$.

\section{IGF-1 Suppresses Th2 Differentiation Instructed by RAR $\alpha$-Activated BMDC}

To figure out whether RAR $\alpha$ regulates th2 cell differentiation, we next compared the ability of BMDCs from RARA ${ }^{\Delta \mathrm{DC}}$ mice and which from $\mathrm{RARA}^{\mathrm{fl} / \mathrm{fl}}$ control mice instruct $\mathrm{T}$ cell responses in vitro. The polarization of CD4(+) T cells was detected by flow cytometry. Our results showed that the proportion of CD4(+)IL4 (+) T cells stimulated by RAR $\alpha$-deficient BMDCs is significantly smaller than which produced by normal BMDCs (Figures 5A, B). Interestingly, RAR $\alpha$-deficient BMDCs also inhibit naive CD4 T cells differentiate to CD4(+)IFN- $\gamma(+) \mathrm{T}$ cells (Figures 5C, D). Furthermore, tamibarotene-stimulated BMDCs also promote the proportion of $\mathrm{CD} 4(+) \mathrm{IL} 4(+) \mathrm{T}$ cells. The previous in vitro experiment indicated that IGF-1 could mitigate RA signaling through the Akt pathway. We use IGF-1 to inhibit the tamibarotene's ability to activate RA signaling. And we found IGF-1 could decrease the number of CD4(+)IL4(+) T cells activated by tamibarotene-stimulated BMDCs (Figures 5E, F). And the ability of tamibarotene-stimulated BMDCs to induce Th2-cell differentiation was repressed by anti-IFN $\alpha$. Collectively, RAR $\alpha$ in dendritic cells has a crucial role in instructing Th2 cell differentiation, and IGF-1 can inhibit this effect.

\section{SCFAs Interfere With Pathological Processes of Food Allergy in ABX-Treated Mice}

Some specific metabolites produced by gut microbiota affect host immune function, and emerging evidence indicates that it is involved in the pathogenesis of several diseases $(27,28)$. SCFAs are the primary microbiota metabolites in the gut. A study demonstrated that supplementation of antibiotic-treated mice with SCFAs restores IGF-1 expression levels in serum and bone. In this experiment, antibiotic depletion of microbiota from normal raised mice reduced serum IGF-1 levels and IGF-1 gene expression in $\mathrm{mLN}$ (Figures 6A, B). Moreover, IGF-1 levels in serum and $\mathrm{mLN}$ are significantly increased in SCFAs-supplemented mice than antibiotic-treated mice (Figures 6A, B). Then we measured transcriptional levels of RA signaling-related genes and type I interferons in $\mathrm{mLN}$ by $\mathrm{qPCR}$, and both were increased in $\mathrm{ABX}$ treated mice, compared with control mice (Figures 6C, D). And we found that after SCFAs supplementation to ABXtreated mice, decreased transcriptional levels of RA-related genes 
A

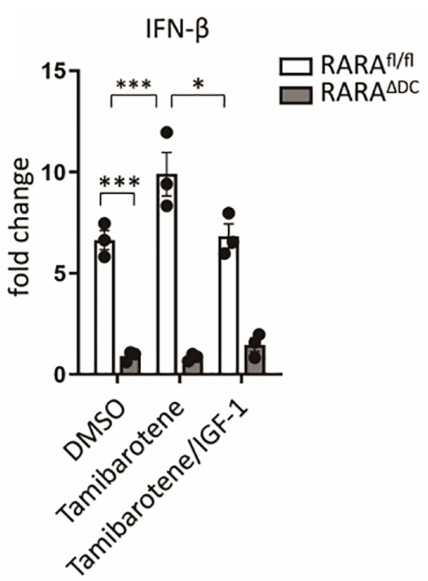

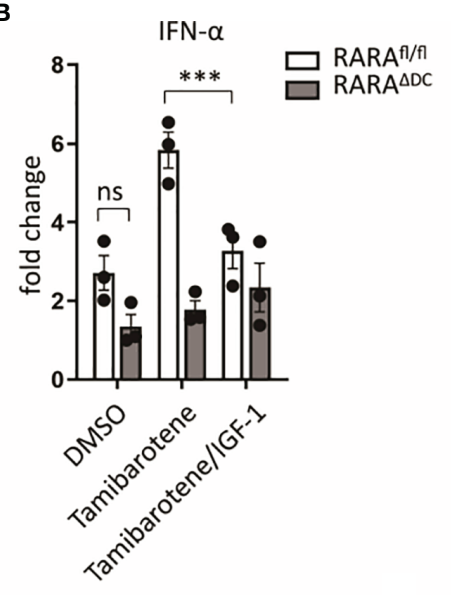

C

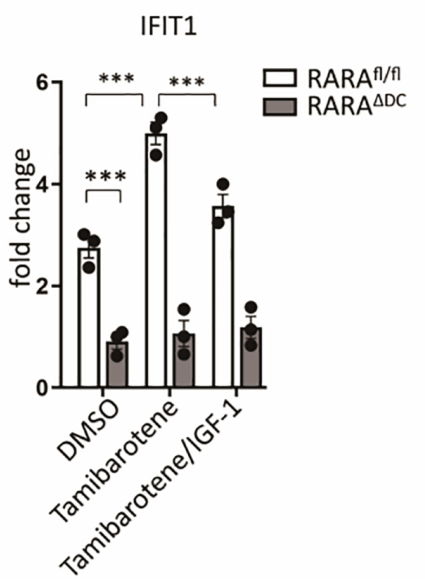

D

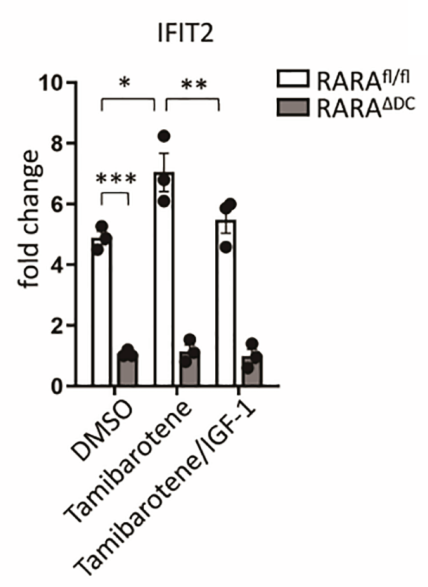

E

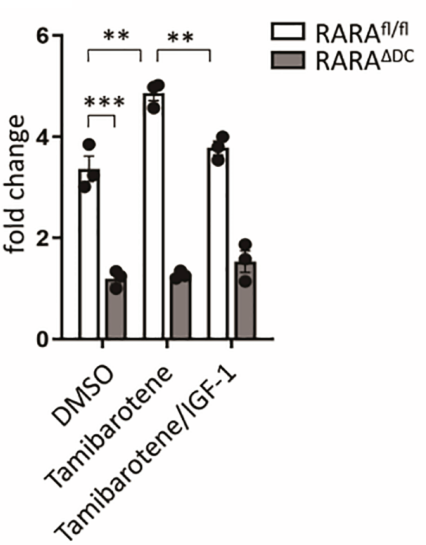

F

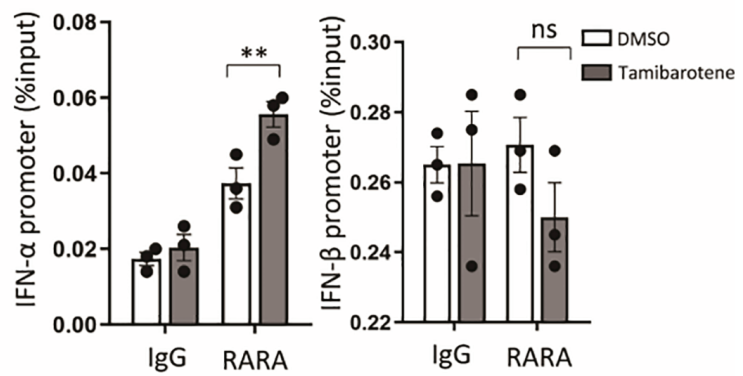

G

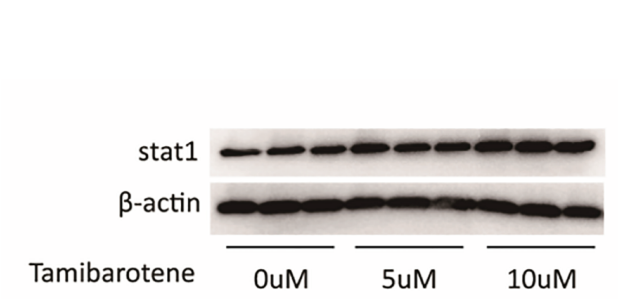

H

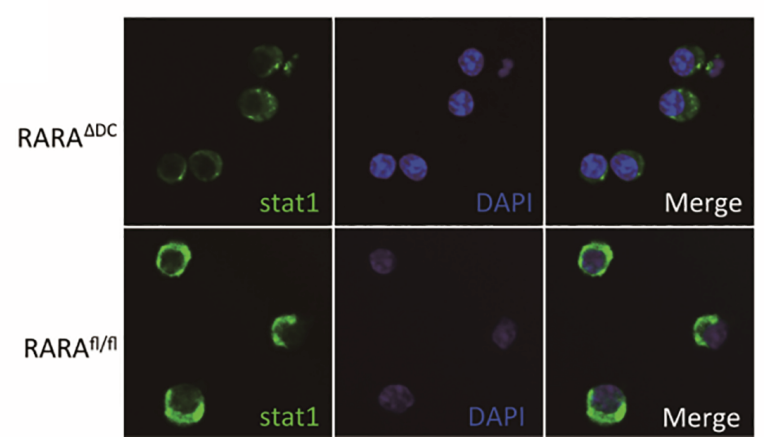

FIGURE 4 | Retinoic acid receptor alpha regulates type I interferons and stat1 expression. (A-E) BMDCs cultured from RAR $\alpha^{\text {fl/fl }}$ and RAR $\alpha^{\Delta \mathrm{DC}}$ mice, were treated with DMSO, Tamibarotene (4mM) alone or with IGF-1 (500ng/ml), then mRNA expression of IFN- $\alpha$, IFN- $\beta$, and ISGs (IFIT1, IFIT2, MX1) were determined by RT-PCR. (F) ChIP-qPCR for RAR $\alpha$ at IFN- $\alpha$, and IFN- $\beta$ regulatory element in BMDCs cultured from SPF mice. (G) BMDCs from SPF mice were treated with different concentration of tamibarotene (respectively OuM, 5uM, 10uM), and stat1 protein expression were measured by western blotting. (H) stat1 expression in BMDCs from $\mathrm{RAR} \alpha^{\mathrm{fl} / \mathrm{fl}}$ and $\mathrm{RAR} \alpha^{\Delta \mathrm{DC}}$ mice were detected by immunofluorescence method. Data are from at least two independent experiments. Graph shows mean and SEM. Data were analyzed by one-way ANOVA. ${ }^{\star} p<0.05$, ${ }^{\star \star} p<0.01$, ${ }^{\star \star \star} p<0.001$. ns, not significant.

and type I interferons' genes were detected compared to mice only treated with ABX (Figures 6C, D).

To explore whether depletion of microbiota could fuel allergic response, an ova-allergic mice model was established. A higher level of ova-specific IgE, IgG1, was detected by ELISA in antibiotics-treated allergic mice compared with control allergic mice (Figure 6E). The antibiotic method also induced an increased number of CD4(+)IL4(+) T cells and a decreased 
A

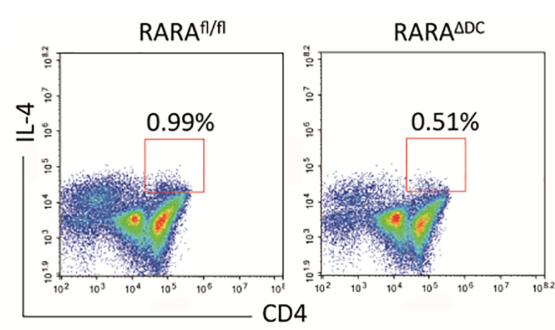

D

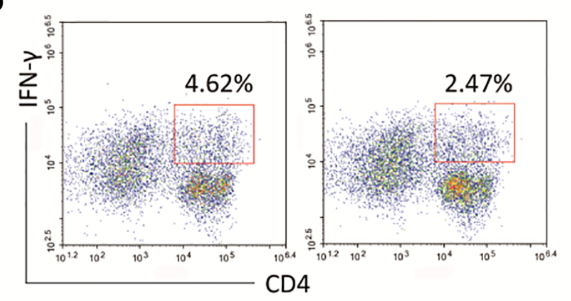

E

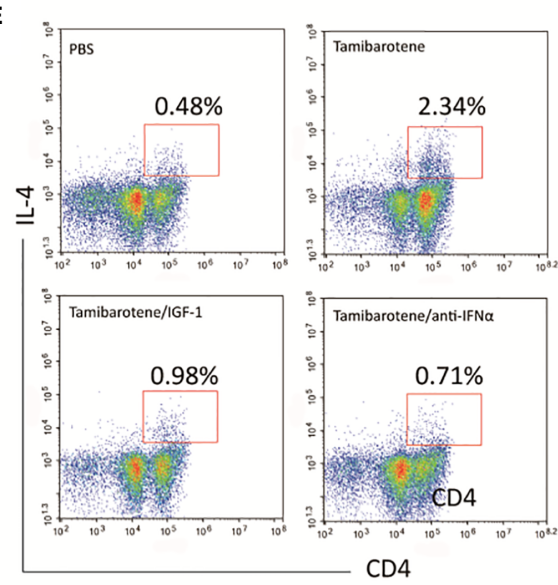

G

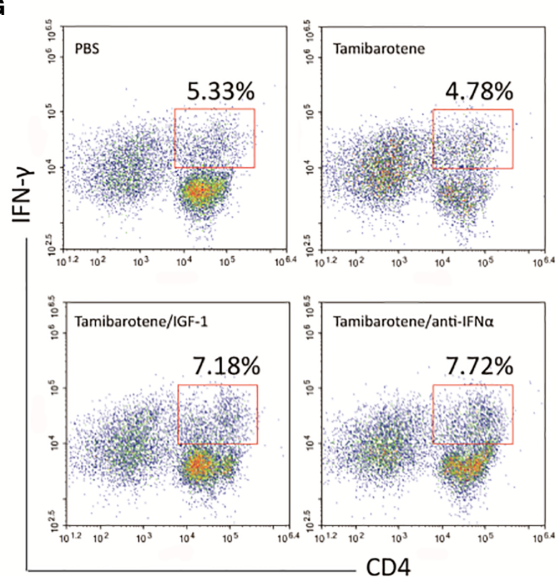

B

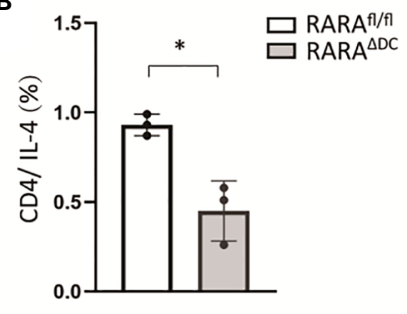

C

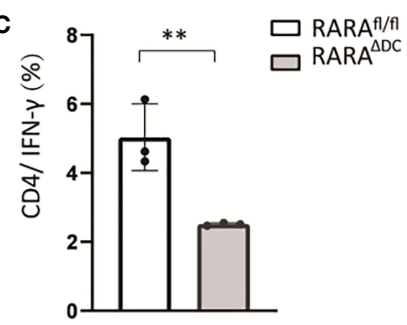

F

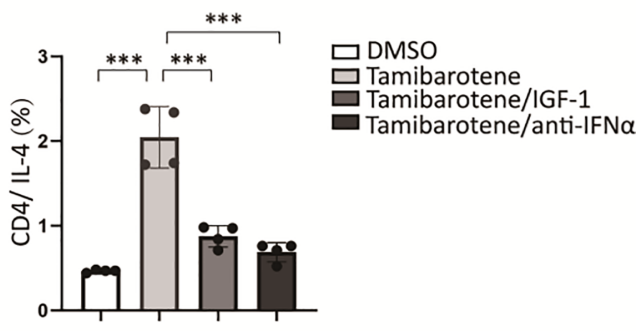

H

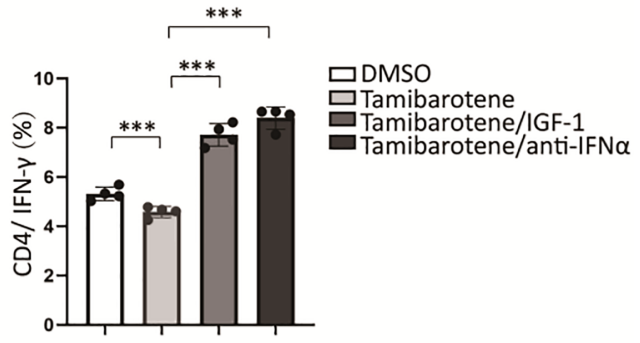

FIGURE 5 | IGF-1 suppresses Th2 differentiation instructed by RAR $\alpha$-activated BMDC. (A-D) After BMDCs from RAR $\alpha^{\text {fl/fl }}$ or RAR $\alpha^{\Delta D C}$ mice co-cultured with naive T cells isolated from B6 mice, the percentage of CD4(+)IL-4(+) T cells and CD4(+)IFN- $\gamma(+) T$ cells were detected by flow cytometry. (E-H) BMDCs from B6 mice were treated with DMSO, Tamibarotene, IGF-1 or anti-IFN $\alpha$, and then co-cultured with naive T cells. Percentage of CD4(+)IL-4(+) cells and CD4(+)IFN- $\gamma(+)$ were measured by flow cytometry. Data are from at least two independent experiments. Graph shows mean and SEM. Data were analyzed by unpaired Student's t-test (A-D) and one-way ANOVA (E-H). ${ }^{*} p<0.05,{ }^{* \star} p<0.01,{ }^{* \star *} p<0.001$. 
A

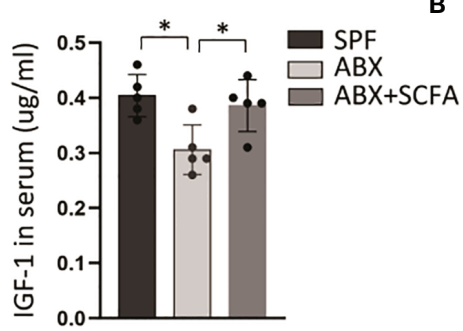

B

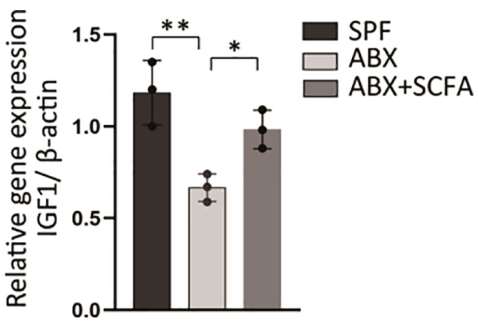

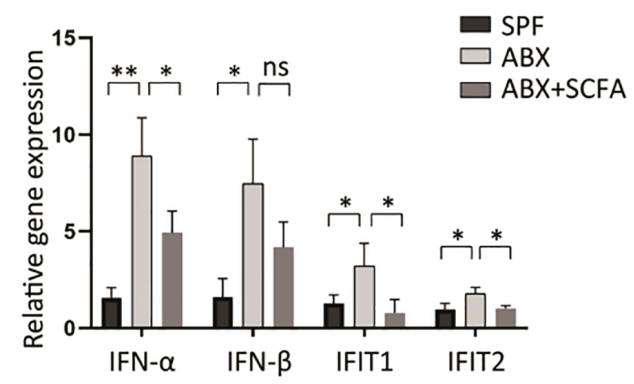

D

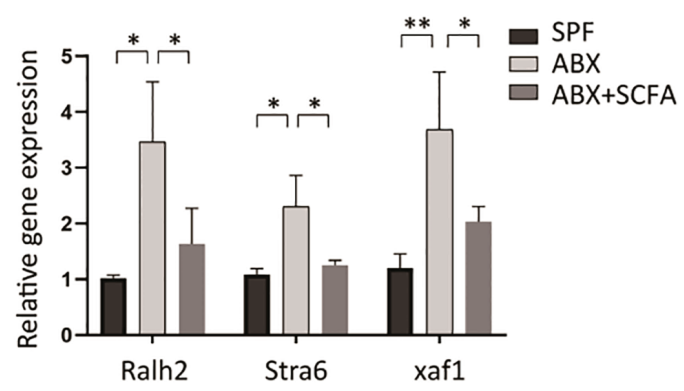

E

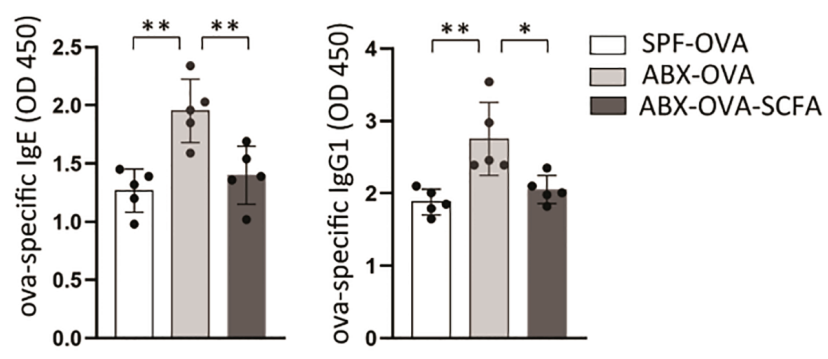

$\mathbf{F}$
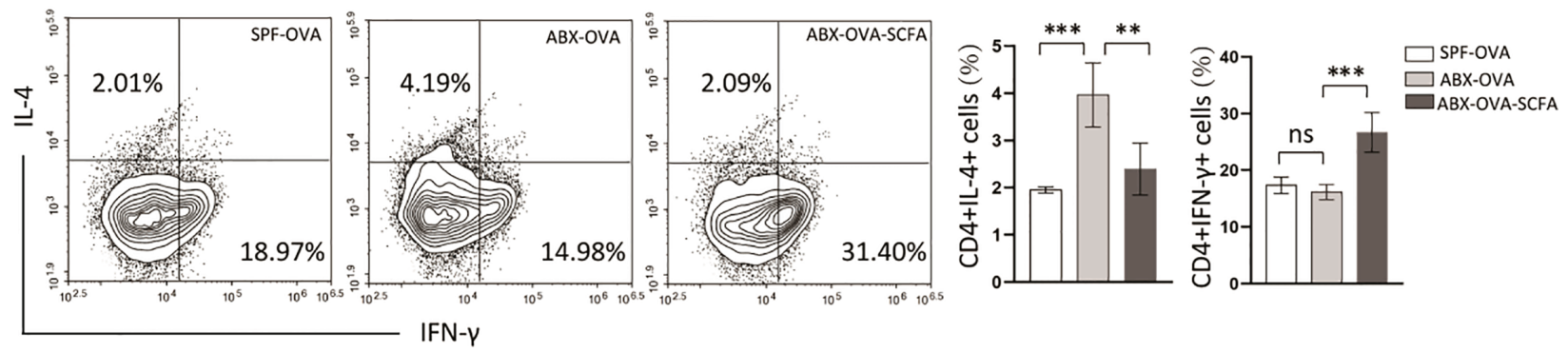

FIGURE 6 SCFAs alleviate OVA-sensitization fueled by microbiota-dysbiosis. B6 Mice were treated with control vehicle, ABX alone, or with SCFA supplement. (A) And then the expression levels of IGF-1 in serum were detected by ELISA. (B) The transcriptional levels of IGF-1 in mLN were measured by RT-PCR.

The transcriptional levels of type I interferons genes $\mathbf{( C )}$ and retinoic acid related genes (D) in $\mathrm{mLN}$ tissue were measured by RT-PCR. Then we established ovaallergic mice model fuled by microbiota dysbiosis with ABX treatment, and SCFAs were used to treat these mice. (E) The ova-specific IgE and lgG1 in serum were detected by ELISA. (F) The proportions of CD4(+)IL4(+), CD4(+)IFN- $\gamma(+)$ cell were detected by flow cytometry. Graph shows mean and SEM. Data were analyzed by one-way ANOVA. ${ }^{*} p<0.05,{ }^{\star *} p<0.01,{ }^{* \star *} p<0.001$. ns, not significant.

number of $\mathrm{CD} 4(+) \operatorname{IFN}-\gamma(+) \mathrm{T}$ cells in mLN compared with control allergic mice (Figures 6E, F). And SCFAs supplementation reduced the ova-specific IgE, ova-specific IgG1 serum levels, and the proportion of CD4(+)IL4(+) T cells compared with antibiotic-treated mice (Figures 6E, F). These data indicated that SCFAs could reverse abnormal activation of RA signaling and IFNI response induced by depletion of gut bacteria, and revealed a contribution of RA 
signaling and type I interferons to intestine allergic response fueled by dysbiotic gut bacteria.

\section{DISCUSSION}

RA, the primary metabolite of vitamin A, serves as the immune regulator and maintains gut homeostasis. Evidence showed that RA secreted mainly from intestinal epithelial and dendritic cells developed to mitigate inflammation in several diseases $(29,30)$. However, studies recently revealed the proinflammatory aspect of RA signaling, which regulates T cell's response by affecting IL-17 and IFN- $\gamma$ secretion $(31,32)$. RAR $\alpha$, a nuclear receptor, served as the most critical transcriptional modulator in RA signaling. Dysregulated T cells response is involved in allergic diseases. This study clarified RAR pplayed a crucial role in food allergy by promoting naive CD4(+) $\mathrm{T}$ cells to differentiate into Th2 cells. The gut microbiota has recently proved to be involved in the pathogenesis of several diseases, including allergic diseases, tumors, and even neurological disorders $(33,34)$. Ablation of gut microbiota early in life could lead to food allergy development by influencing the immune system development (33). In this study, we demonstrated a direct role of gut bacteria in regulation of RA signaling. After $\mathrm{ABX}$ treatment to mice, we found an increasing level of RA-related genes and type I interferons (Figures 6C, D). We hypothesis that RA signaling and type I interferons are involved in the pathogenesis of food allergy. In an ova-allergic mice model, cd $11 c^{\mathrm{cre}} \mathrm{RARA}^{\mathrm{fl} / \mathrm{fl}}$ mice presented a decreased number of CD4(+)IL4(+) T cells in $\mathrm{mLN}$ and reduction of ova-specific IgE, IgG1 level in serum compared with RARA ${ }^{\mathrm{f} / \mathrm{fl}}$ control mice (Figures 1F-H).

Evidence indicates reducing serum IGF-1 level after ablation of gut microbes (35), resulting in an abnormality of bone formation directly (20). In WT mice, we observed a significant reduction of serum IGF-1 level and IGF-1 expression in mLN after ABX treatment (Figures 2A, B). These results indicated IGF-1 might be involved in the regulatory pathway in intestinal diseases associate with microbiota deficiency. In vitro experiment revealed that IGF-1 negatively regulates RA signaling (Figures 3A, B) and type I interferons expression (Figures 4A-E) activated by tamibarotene RAR $\alpha$ specific agonist.

RAR $\alpha$ transactivation is activated by RA directly and is also regulated by Phosphorylation, and RAR $\alpha$ phosphorylation is proved to contribute to inhibit RA signaling in lung cancers (36). Protein kinase A (PKA), PKC, p38 are considered to phosphorylate retinoic acid receptors (37-39). Another serine/ threonine kinase, Akt, is a downstream target of the PI3K pathway and inhibits RAR $\alpha$ 's transactivation by phosphorylating the Ser ${ }^{96}$ site of RAR $\alpha$ (21). We showed that tamibarotene increased the transcriptional level of RARE element in BMDCs from the RARE report mice (Figures 3A, B) and decreased the phosphorylation level of RAR $\alpha$ at the $\operatorname{Ser}^{77}$ site (Figures 3C, D). These results indicated that the phosphorylation of RAR $\alpha$ could restrict RA signaling activated by tamibarotene. And it is plausible that Akt, which increases the Phosphorylation of $\operatorname{RAR} \alpha$, is involved in the inhibition of RA signaling by IGF-1. Taken together, IGF-1 may inhibit RA signaling by enhancing the process of RAR $\alpha$ Phosphorylation by Akt.

IFN- $\alpha$ and IFN- $\beta$, the prominent members of Type I interferons, are crucial for the maturation or differentiation of innate immune cells, especially dendritic cells (40). BMDCs from Ifnar1/2-/- mice showed a decreased expression of costimulatory factors and a suppressed state of activation compared to wild-type mice $(12,41)$.

In BMDCs from RARA ${ }^{\Delta \mathrm{DC}}$ mice, the expression level of IFN- $\alpha$, IFN- $\beta$, and several interferon-stimulated genes was significantly decreased compared with control mice (Figures 4A-E). According to these results, we came up with the hypotheses that IGF-1 may regulate type I interferon expression by regulating the RAR $\alpha$ pathway. By performing the CHIP experiment in BMDCs from WT mice, we clarified that RAR $\alpha$ is bound to the promoter of IFN$\alpha$ (Figure 4F) but not IFN- $\beta$. Although the previous study showed RAR $\alpha$ targeted stat1 promoter, we did not detect the bond of stat1 and RAR $\alpha$ by the CHIP experiment (data not shown). However, we found a decreased stat1 protein level in BMDCs from RARA ${ }^{\triangle D C}$ mice compared with those from $\mathrm{RARA}^{\mathrm{fl} / \mathrm{fl}}$ control mice (Figure 4H). And RAR $\alpha$ agonist enhanced the expression of stat1 protein in a dose-dependent experiment (Figure 4G). Hence, we concluded that the expression of type I interferons in BMDCs is affected by the transcriptional level of IFN- $\alpha$ targeted by the transcription factor, RAR $\alpha$.

Consist of animal experiments, RAR $\alpha$-deficient BMDCs significantly inhibit naive CD4 $\mathrm{T}$ cells differentiate to CD4(+) IL4(+) T cells (Figures 5A, B). And tamibarotene, the RAR $\alpha$ specific agonist, enhanced the initiation of Th2 differentiation (Figures 5E, F). Interestingly, we found that IGF-1 could mitigate the activation of Th2 differentiation induced by the RAR $\alpha$ agonist (Figures 5E, F). And we suggested that IGF-1's inhibition of RAR $\alpha$ transcriptional activity and Type I interferon expression might be involved in the inhibition of Th2 cells differentiation of naive $\mathrm{T}$ cells in vitro. In IFNAR-deficient mice, type 2 immunity was reduced in the absence of IFNI signaling in silica-exposed M. tuberculosis-infected mice (42). Exposure with IFNa increases the sensitivity of T cells to IL-4 and enhances the induction of STAT6 activation (43).

As one of the most studied bacterial metabolites, SCFAs play a core role in mucosal integrity and implicate immune response regulation. In food-allergic children, a decreased level of fecal SCFAs, particularly butyrate, has been described compared to healthy children (44). Acetate, propionate and butyrate are main SCFA, which are substrates for gut bacterial fermentation. In this study, we made a mixture of SCFAs, including acetate, propionate and butyrate. We observed the protective effect in allergic mice after SCFAs supplement. However the specific SCFA for regulation of allergic response should be further studied.

In vivo experiment, we demonstrated that SCFAs attenuated ova-allergic responses enhanced by ABX treatment (Figures 6E-G). In $\mathrm{ABX}$ mice, we observed that the supplement of SCFAs restored decreased IGF-1 expression level in mLN caused by antibiotics treatment (Figure 6B). Antibiotics treatment strongly activated RArelated gene expression and type I interferons expression in $\mathrm{mLN}$ and suppressed by SCFAs supplement (Figures 6C, D). 
These results provoke the hypothesis that limiting the RA signaling and type I interferons via SCFAs could be a mechanism by which gut commensals inhibit allergic response.

In conclusion, we show that gut commensals plays a protective role in the regulation of allergic response in an mice model. Our current work establish a clear link between RA signaling activation in state of dysbiotic community and its effect on type I interferons. However, exact signaling mechanism that SCFAs affect IGF-1 production remains unclear. And the specific microbiota and its mechanism which play a role in state of dysbiotic gut homeostasis fueling allergy should be further determined. Current work identified $R A R \alpha$ was involved in regulation of allergic response by driving Th2 cells differentiation of naive CD4 T cells. As IGF-1 inhibits Th2 differentiation of naive $\mathrm{T}$ cells by interfering with type I interferons expression in dendritic cells through Akt/RAR $\alpha$ pathway, microbiota metabolites SCFAs might attenuate allergic response by maintaining IGF-1 expression. This study reveals that control of RA signaling might be a potential strategy for intervention in allergic diseases in which dysbiotic gut commensals was observed.

\section{MATERIALS AND METHODS}

\section{Mice}

RARE-lacZ transgenic mice, OT-II transgenic mice, were all on a C57BL/ 6 background and obtained from Jackson Laboratories. $\mathrm{CD} 11 c^{\mathrm{cre}}$, RAR $\alpha^{\mathrm{fl} / \mathrm{fl}}$ mice, and $\mathrm{C} 57 \mathrm{BL} / 6$ mice were purchased from GemPharmatech. All mice were bred and maintained at the southwest medical university under specific pathogen-free conditions. Experiments were approved from the affiliated hospital of the southwest medical university animal ethics committee and consistent with the NIH guidelines.

\section{Antibiotics and SCFA Treatment}

For antibiotics treatment experiments, mice were bred with antibiotics mixed in pathogens-free water for 2 months. The antibiotics cocktail contained vancomycin $(500 \mathrm{mg} / \mathrm{l})$, metronidazole (40mg/l), Kanamycin (80mg/l), Gentamycin $(7 \mathrm{mg} / \mathrm{l})$, and Colistin $(9 \mathrm{mg} / \mathrm{l})$. For SCFA supplementation experiments, mice were firstly fed with $\mathrm{ABX}$ water for two weeks, and then SCFAs $(67.5 \mathrm{mM}$ acetate, $40 \mathrm{mM}$ butyrate, $25.9 \mathrm{mM}$ propionate) were added to $\mathrm{ABX}$ water for 1.5 months.

\section{Food Allergy Mice Model}

Mice were intragastrical sensitized with $2 \mathrm{mg}$ of ova and $15 \mathrm{ug}$ of CT as adjuvant once a week for five weeks. Control mice were treated with PBS only. On day 35, mice were intragastrical challenged with $20 \mathrm{mg}$ of mice alone. On day 36 , mice were sacrificed for sample collection.

\section{Cell Culture}

For BMDC generation, bone marrow cells obtained from femurs and tibia of adult mice were cultured at $37^{\circ} \mathrm{C}$ and $5 \% \mathrm{CO}_{2}$ in RPMI 1640 (Hyclone) containing 10\% FBS, 10mM HEPES, 2mM L-glutamine, 50mM 2-mercaptoethanol (Sigma), $50 \mathrm{U} /$ $\mathrm{ml}$ penicillin, and 50ug/ml streptomycin. The culture medium was added with cytokines IL4 and GMSCF (PeproTech) on day 2. Day 5 BMDCs were harvest on day seven and exposed to $4 \mathrm{mM}$ tamibarotene, 500ng/ml IGF-1, 5ug/ml OVA, respectively, for experiments. For BMDC-T cell co-culture, naive $\mathrm{T}$ cells were isolated by $\mathrm{CD} 4(+)$ negative separation Kit (Stemcells) from OTII mice and co-cultured with BMDCs at a ratio of 1:2 in the presence of ova for three days. Cells were prepared for flow cytometry analysis.

\section{Flow Cytometry Analysis}

Single-cell suspensions were incubated in ice-cold flow cytometry buffer and stained with fluorochrome-conjugated antibodies purchased from eBioscience: cd11c, b220, cd4, Biolegend. For analysis of secreting cytokines, cells were incubated in the presence of PMA, and Ionomycin for $4 \mathrm{~h}$, and $10 \mathrm{ug} / \mathrm{ml}$ brefeldin A for $2 \mathrm{~h}$. BMDCs generated from RARE-lacZ transgenic mice were stimulated with tamibarotene, IGF-1 for $3 \mathrm{~h}$ and resuspended with DDAOG for $0.5 \mathrm{~h}$ at $4^{\circ} \mathrm{C}$. RA activity was identified by Flow cytometry, measuring the signal of DDAOG to DDAO conversion.

\section{CHIP}

All experimental procedures were instructed by the manufacturer instruction of the CHIP kit (ThermoFisher Scientific). After sonication, cells were broken and immunoprecipitated by antiRAR $\alpha$ (Diagenode). Samples were treated with proteinase K, heated to de-cross linking, and purified with columns. Rabbit IgG was used as a negative control. Immunoprecipitated chromatin was subjected to quantitative PCR analysis with primers targeting the promoters of IFN- $\alpha$, IFN- $\beta$. The two pairs of primers were designed as follows:

IFN- $\alpha$ (sense 1:5'GAAGTTCACCCCAATGATCTG 3', sense 2:5'GGGCTATAGATGTGCTGAACTG 3'),

IFN- $\beta$ (sense 1: 5' TGACTAAGGGCAAAGTGAGATT 3', sense 2: 5' TTCACATTCCTTTATTTGGTCAT 3’)

\section{qPCR}

Mesenteric lymph nodes tissues were ground into single cells. Total RNA was extracted using the Total RNA Isolation Kit (Vazymy). And cDNA was synthesized with a cDNA Synthesis Kit (Vazymy). Real-time PCR was performed on LightCycler480 (Roche) using SYBR Green Master Mix (Vazymy). Gene expression was normalized to $\beta$-actin and calculated using the $\Delta \Delta \mathrm{Ct}$ method.

\section{Protein Analysis}

ELISA detected concentrations of IGF-1 in serum according to the manufacturer's instruction (Boster). Immunoblot analysis was performed with an antibody to RAR $\alpha$, and RAR $\alpha$ phosphorylated at Ser77, antibody to Akt and Akt phosphorylated at Ser473, antibody to stat1, antibody to $\beta$-actin (all from Abcam).

\section{Statistical Analysis}

All statistical analyses were performed in Graphpad Prism software (version 8 ), and data were analyzed by unpaired Student's t-test 
and one-way ANOVA whenever necessary. $\mathrm{P}<0.05$ was considered significant. All data represent means \pm SEM.

\section{DATA AVAILABILITY STATEMENT}

The raw data supporting the conclusions of this article will be made available by the authors, without undue reservation.

\section{ETHICS STATEMENT}

Experiments were approved from the Affiliated Hospital of the Southwest Medical University animal ethics committee and consistent with the NIH guidelines.

\section{REFERENCES}

1. Erkelens MN, Mebius RE. Retinoic Acid and Immune Homeostasis: A Balancing Act. Trends Immunol (2017) 38(3):168-80. doi: 10.1016/j.it.2016.12.006

2. Larange A, Cheroutre H. Retinoic Acid and Retinoic Acid Receptors as Pleiotropic Modulators of the Immune System. Annu Rev Immunol (2016) 34:369-94. doi: 10.1146/annurev-immunol-041015-055427

3. Mora JR, Bono MR, Manjunath N, Weninger W, Cavanagh LL, Rosemblatt $\mathrm{M}$, et al. Selective Imprinting of Gut-Homing T Cells by Peyer's Patch Dendritic Cells. Nature (2003) 424(6944):88-93. doi: 10.1038/nature01726

4. Stagg AJ, Kamm MA, Knight SC. Intestinal Dendritic Cells Increase T Cell Expression of Alpha4beta7 Integrin. Eur J Immunol (2002) 32(5):1445-54. doi: 10.1002/1521-4141(200205)32:5<1445::AID-IMMU1445>3.0.CO;2-E

5. Galvin KC, Dyck L, Marshall NA, Stefanska AM, Walsh KP, Moran B, et al. Blocking Retinoic Acid Receptor-Alpha Enhances the Efficacy of a Dendritic Cell Vaccine Against Tumours by Suppressing the Induction of Regulatory T Cells. Cancer Immunol Immunother (2013) 62(7):1273-82. doi: 10.1007/ s00262-013-1432-8

6. Lyu Y, Wu L, Wang F, Shen X, Lin D. Carotenoid Supplementation and Retinoic Acid in Immunoglobulin A Regulation of the Gut Microbiota Dysbiosis. Exp Biol Med (Maywood) (2018) 243(7):613-20. doi: 10.1177/ 1535370218763760

7. Rooks MG, Garrett WS. Gut Microbiota, Metabolites and Host Immunity. Nat Rev Immunol (2016) 16(6):341-52. doi: 10.1038/nri.2016.42

8. Chang PV, Hao L, Offermanns S, Medzhitov R. The Microbial Metabolite Butyrate Regulates Intestinal Macrophage Function via Histone Deacetylase Inhibition. Proc Natl Acad Sci USA (2014) 111(6):2247-52. doi: 10.1073/pnas.1322269111

9. Mazmanian SK, Liu CH, Tzianabos AO, Kasper DL. An Immunomodulatory Molecule of Symbiotic Bacteria Directs Maturation of the Host Immune System. Cell (2005) 122(1):107-18. doi: 10.1016/j.cell.2005.05.007

10. Palm NW, Rosenstein RK, Medzhitov R. Allergic Host Defences. Nature (2012) 484(7395):465-72. doi: 10.1038/nature11047

11. Kurche JS, Haluszczak C, McWilliams JA, Sanchez PJ, Kedl RM. Type I IFNDependent T Cell Activation Is Mediated by IFN-Dependent Dendritic Cell OX40 Ligand Expression and Is Independent of T Cell IFNR Expression. J Immunol (2012) 188(2):585-93. doi: 10.4049/jimmunol.1102550

12. Montoya M, Schiavoni G, Mattei F, Gresser L, Belardelli F, Borrow P, et al. Type I Interferons Produced by Dendritic Cells Promote Their Phenotypic and Functional Activation. Blood (2002) 99(9):3263-71. doi: 10.1182/blood.V99.9.3263

13. Webb LM, Lundie RJ, Borger JG, Brown SL, Connor LM, Cartwright AN, et al. Type I Interferon Is Required for T Helper (Th) 2 Induction by Dendritic Cells. EMBO J (2017) 36(16):2404-18. doi: 10.15252/embj.201695345

14. McDonald KG, Leach MR, Brooke KWM, Wang C, Wheeler LW, Hanly EK, et al. Epithelial Expression I of the Cytosolic Retinoid Chaperone Cellular Retinol Binding Protein II Is Essential for In Vivo Imprinting of Local Gut Dendritic Cells by Lumenal Retinoids. Am J Pathol (2012) 180(3):984-97. doi: 10.1016/j.ajpath.2011.11.009

\section{AUTHOR CONTRIBUTIONS}

ZZ conceived the study. XY and ZZ wrote the manuscript. XY, HT, RW, XL, and HJ performed the experiments. ZL helped with manuscript writing and data discussion. All authors contributed to the article and approved the submitted version.

\section{FUNDING}

This work was supported by the National Natural Science Foundation of China (number 82001703); open funding from the Key Laboratory of Allergy and Immunology, Shenzhen University, and the Shenzhen Science and Technology Peacock Team Project (number KQTD20170331145453160).

15. Zeng R, Oderup C, Yuan R, Lee M, Habtezion A, Hadeiba H, et al. Retinoic Acid Regulates the Development of a Gut-Homing Precursor for Intestinal Dendritic Cells. Mucosal Immunol (2013) 6(4):847-56. doi: 10.1038/mi.2012.123

16. Bhattacharya N, Yuan R, Prestwood TR, Penny HL, Dimaio MA, RetickerFlynn NE, et al. Normalizing Microbiota-Induced Retinoic Acid Deficiency Stimulates Protective CD8(+) T Cell-Mediated Immunity in Colorectal Cancer. Immunity (2016) 45(3):641-55. doi: 10.1016/j.immuni.2016.08.008

17. Zhang Z, Li JJ, Zheng W, Zhao G, Zhang H, Wang X, et al. Peripheral Lymphoid Volume Expansion and Maintenance Are Controlled by Gut Microbiota via RALDH+ Dendritic Cells. Immunity (2016) 44(2):330-42. doi: 10.1016/j.immuni.2016.01.004

18. Shida K, Takahashi R, Iwadate E, Takamizawa K, Yasui H, Sato T, et al. Lactobacillus Casei Strain Shirota Suppresses Serum Immunoglobulin E and Immunoglobulin G1 Responses and Systemic Anaphylaxis in a Food Allergy Model. Clin Exp Allergy (2002) 32(4):563-70. doi: 10.1046/j.09547894.2002.01354.x

19. Wu R, Li X, Ma N, Jin X, Yuan X, Chen Q, et al. Bacterial Quorum Sensing Molecules Promote Allergic Airway Inflammation by Activating the Retinoic Acid Response. iScience (2020) 23(7):101288. doi: 10.1016/j.isci.2020.101288

20. Yan J, Herzog JW, Tsang K, Brennan CA, Bower MA, Garrett WS, et al. Gut Microbiota Induce IGF-1 and Promote Bone Formation and Growth. Proc Natl Acad Sci USA (2016) 113(47):E7554-63. doi: 10.1073/pnas.1607235113

21. Srinivas H, Xia D, Moore NL, Uray IP, Kim H, Ma L, et al. Akt Phosphorylates and Suppresses the Transactivation of Retinoic Acid Receptor Alpha. Biochem $J$ (2006) 395(3):653-62. doi: 10.1042/BJ20051794

22. Soumelis V, Reche PA, Kanzler H, Yuan W, Edward G, Homey B, et al. Human Epithelial Cells Trigger Dendritic Cell Mediated Allergic Inflammation by Producing TSLP. Nat Immunol (2002) 3(7):673-80. doi: $10.1038 /$ ni805

23. Pellefigues C, Tang SC, Schmidt A, White RF, Lamiable O, Connor LM, et al. Toll-Like Receptor 4, But Not Neutrophil Extracellular Traps, Promote IFN Type I Expression to Enhance Th2 Responses to Nippostrongylus Brasiliensis. Front Immunol (2017) 8:1575. doi: 10.3389/fimmu.2017.01575

24. Connor LM, Tang SC, Cognard E, Ochiai S, Hilligan KL, Old SI, et al. Th2 Responses Are Primed by Skin Dendritic Cells With Distinct Transcriptional Profiles. J Exp Med (2017) 214(1):125-42. doi: 10.1084/jem.20160470

25. Kolla V, Weihua X, Kalvakolanu DV. Modulation of Interferon Action by Retinoids. Induction of Murine STAT1 Gene Expression by Retinoic Acid. J Biol Chem (1997) 272(15):9742-8. doi: 10.1084/jem.20160470

26. Tisserand J, Khetchoumian K, Thibault C, Dembele D, Chambon P, Losson R. Tripartite Motif 24 (Trim24/Tiflalpha) Tumor Suppressor Protein Is a Novel Negative Regulator of Interferon (IFN)/signal Transducers and Activators of Transcription (STAT) Signaling Pathway Acting Through Retinoic Acid Receptor Alpha (Raralpha) Inhibition. J Biol Chem (2011) 286(38):3336979. doi: 10.1074/jbc.M111.225680

27. Quigley EMM. Microbiota-Brain-Gut Axis and Neurodegenerative Diseases. Curr Neurol Neurosci Rep (2017) 17(12):94. doi: 10.1007/s11910-017-0802-6 
28. Codella R, Luzi L, Terruzzi I. Exercise has the Guts: How Physical Activity may Positively Modulate Gut Microbiota in Chronic and Immune-Based Diseases. Dig Liver Dis (2018) 50(4):331-41. doi: 10.1016/j.dld.2017.11.016

29. Povoleri GAM, Nova-Lamperti E, Scottà C, Fanelli G, Chen YC, Becker PD, et al. Human Retinoic Acid-Regulated CD161(+) Regulatory T Cells Support Wound Repair in Intestinal Mucosa. Nat Immunol (2018) 19(12):1403-14. doi: 10.1038/s41590-018-0230-Z

30. Mucida D, Park Y, Kim G, Turovskaya O, Scott I, Kronenberg M, et al. Reciprocal TH17 and Regulatory T Cell Differentiation Mediated by Retinoic Acid. Science (2007) 317(5835):256-60. doi: 10.1126/science.1145697

31. Hall JA, Cannons JL, Grainger JR, Santos LMD, Hand TW, Naik S, et al. Essential Role for Retinoic Acid in the Promotion of CD4(+) T Cell Effector Responses via Retinoic Acid Receptor Alpha. Immunity (2011) 34(3):435-47. doi: 10.1016/j.immuni.2011.03.003

32. Cha HR, Chang SY, Chang JH, Kim JO, Yang JY, Kim CH, et al. Downregulation of Th17 Cells in the Small Intestine by Disruption of Gut Flora in the Absence of Retinoic Acid. J Immunol (2010) 184(12):6799-806. doi: 10.4049/jimmunol.0902944

33. Stephen-Victor E, Crestani E, Chatila TA. Dietary and Microbial Determinants in Food Allergy. Immunity (2020) 53(2):277-89. doi: 10.1016/j.immuni.2020.07.025

34. Sampson TR, Debelius JW, Thron T, Janssen S, Shastri GG, Ilhan ZE, et al. Gut Microbiota Regulate Motor Deficits and Neuroinflammation in a Model of Parkinson's Disease. Cell (2016) 167(6):1469-80.e12. doi: 10.1016/j.cell.2016.11.018

35. La Grutta S, Maggio C, Giuffrè M, Carta M, Teresi S, Liotta A, et al. Evaluation of IGF1 and IGFBP3 During Diet Therapy in Patients With Food Allergy With Complex Nutritional Risk. Minerva Pediatr (1996) 48(7-8):303-7.

36. Srinivas H, Juroske DM, Kalyankrishna S, Cody DD, Price RE, Xu XC, et al. CJun N-Terminal Kinase Contributes to Aberrant Retinoid Signaling in Lung Cancer Cells by Phosphorylating and Inducing Proteasomal Degradation of Retinoic Acid Receptor Alpha. Mol Cell Biol (2005) 25(3):1054-69. doi: 10.1128/MCB.25.3.1054-1069.2005

37. Lee J, Kim TH, Murray F, Li X, Choi SS, Broide DH, et al. Cyclic AMP Concentrations in Dendritic Cells Induce and Regulate Th2 Immunity and Allergic Asthma. Proc Natl Acad Sci USA (2015) 112(5):1529-34. doi: 10.1073/pnas.1417972112

38. Rochette-Egly C, Oulad-Abdelghani M, Staub A, Pfister V, Scheuer I, Chambon $\mathrm{P}$, et al. Phosphorylation of the Retinoic Acid Receptor-Alpha by Protein Kinase A. Mol Endocrinol (1995) 9(7):860-71. doi: 10.1210/mend.9.7.7476969
39. Delmotte MH, Tahayato A, Formstecher P, Lefebvre P. Serine 157, a Retinoic Acid Receptor Alpha Residue Phosphorylated by Protein Kinase C In Vitro, Is Involved in RXR.RARalpha Heterodimerization and Transcriptional Activity. J Biol Chem (1999) 274(53):38225-31. doi: 10.1074/jbc.274.53.38225

40. Longhi MP, Trumpfheller C, Idoyaga J, Caskey M, Matos I, Kluger C, et al. Dendritic Cells Require a Systemic Type I Interferon Response to Mature and Induce CD4+ Th1 Immunity With Poly IC as Adjuvant. J Exp Med (2009) 206 (7):1589-602. doi: 10.1084/jem.20090247

41. Ma Y, Shurin GV, Peiyuan Z, Shurin MR. Dendritic Cells in the Cancer Microenvironment. J Cancer (2013) 4(1):36-44. doi: 10.7150/jca.5046

42. Benmerzoug S, Bounab B, Rose S, Gosset D, Biet F, Cochard T, et al. Sterile Lung Inflammation Induced by Silica Exacerbates Mycobacterium Tuberculosis Infection via STING-Dependent Type 2 Immunity. Cell Rep (2019) 27(9):2649-64.e5. doi: 10.1016/j.celrep.2019.04.110

43. Eriksen KW, Sommer VH, Woetmann A, Rasmussen AB, Brender C, Svejgaard A, et al. Bi-Phasic Effect of Interferon (IFN)-Alpha: IFN-Alpha Up- and Down-Regulates Interleukin-4 Signaling in Human T Cells. J Biol Chem (2004) 279(1):169-76. doi: 10.1074/jbc.M310472200

44. Roduit C, Frei R, Ferstl R, Loeliger S, Westermann P, Rhyner C, et al. High Levels of Butyrate and Propionate in Early Life Are Associated With Protection Against Atopy. Allergy (2019) 74(4):799-809. doi: 10.1111/ all. 13660

Conflict of Interest: The authors declare that the research was conducted in the absence of any commercial or financial relationships that could be construed as a potential conflict of interest.

Publisher's Note: All claims expressed in this article are solely those of the authors and do not necessarily represent those of their affiliated organizations, or those of the publisher, the editors and the reviewers. Any product that may be evaluated in this article, or claim that may be made by its manufacturer, is not guaranteed or endorsed by the publisher.

Copyright (c) 2021 Yuan, Tang, Wu, Li, Jiang, Liu and Zhang. This is an open-access article distributed under the terms of the Creative Commons Attribution License (CC BY). The use, distribution or reproduction in other forums is permitted, provided the original author(s) and the copyright owner(s) are credited and that the original publication in this journal is cited, in accordance with accepted academic practice. No use, distribution or reproduction is permitted which does not comply with these terms. 